\title{
Burkholderia pseudomallei-absent soil bacterial community results in secondary metabolites that kill this pathogen
}

\author{
Chotima Potisap ${ }^{1}$, Md Abdul Wadud Khan², Atcha Boonmee, Jorge L. M. Rodrigues ${ }^{4}$, \\ Surasakdi Wongratanacheewin ${ }^{5}$ and Rasana W. Sermswan ${ }^{1 *}$ (D)
}

\begin{abstract}
Burkholderia pseudomallei is a Gram-negative bacterium found in soil and the causative agent of a severe disease in humans and animals known as melioidosis. It is intrinsically resistant to many antibiotics and has been reported resistant to the drugs of choice; ceftazidime. Microbial communities in soil in the presence and absence of B. pseudomallei were investigated using metagenomics approach. The variation in bacterial species diversity was significantly higher in soil samples without B. pseudomallei. Abundances of phyla Actinobacteria and Firmicutes were found significantly higher in B. pseudomallei-negative soils. Bacillus amyloliquefaciens KKU1 in phylum Firmicutes was discovered from negative soil and its secondary metabolites could inhibit clinical, environmental and drug resistant isolates of B. pseudomallei, together with some pathogenic Gram-negative but not Gram-positive bacteria. The antimicrobial activity from KKU 1 against B. pseudomallei was abolished when treated with proteinase $\mathrm{K}$, stable in a wide range of $\mathrm{pH}$ and remained active after heating at $100^{\circ} \mathrm{C}$ for $15 \mathrm{~min}$. Precipitated proteins from KKU1 were demonstrated to cause lysis and corrugated surfaces of $B$. pseudomallei. The minimum inhibitory concentrations and minimum bactericidal concentrations of the precipitated proteins from KKU1 against B. pseudomallei were $0.97 \mu \mathrm{g} / \mathrm{ml}$ and $3.9 \mu \mathrm{g} / \mathrm{ml}$. Interestingly, Native SDS-PAGE showed small active compounds of less than $6 \mathrm{kDa}$, along with other information collectively suggesting the properties of antimicrobial peptides. For the first time, culture-independent information in melioidosis endemic area could lead to a suspected source of metabolites that may help defense against B. pseudomallei and other pathogenic Gram-negative bacteria.
\end{abstract}

Keywords: Bacillus amyloliquefaciens, Burkholderia pseudomallei, Metagenomics, Secondary metabolites, Soil

\section{Introduction}

Soil is considered to be a complex environment and is a major reservoir of living organisms either as competitive or symbiotic microbial communities (Robe et al. 2003). Burkholderia pseudomallei is a saprophytic Gramnegative, motile, non-spore-forming bacterium found in soil and water in endemic areas of tropical countries (Wiersinga et al. 2012). It is the causative agent of a severe infectious disease called melioidosis (Cheng and

\footnotetext{
*Correspondence: rasana@kku.ac.th

${ }^{1}$ Melioidosis Research Center and Department of Biochemistry, Faculty of Medicine, Khon Kaen University, 123 Mitraparb Rd, Muang District, Khon Kaen Province 40002, Thailand

Full list of author information is available at the end of the article
}

Currie 2005). The bacterium is intrinsically resistant to several antibiotics (Schweizer 2012). The drugs of choice is ceftazidime, the third-generation cephalosporins, that used to treat severe sepsis cases that have at least a $40 \%$ mortality and a vaccine is not yet available (Wiersinga et al. 2012). Importantly, a few cases of melioidosis have been reported as resistant to the drug (Schweizer 2012). Humans and animals may get infected via inhalation, ingestion but more commonly through an open wound by soil or water contaminated with the bacterium (Barnes and Ketheesan 2005). Because the bacterium can survive through the dry season perhaps by biofilm protection and then expand during a rainy season, soil is therefore 
the most important reservoir of the disease (Inglis and Sagripanti 2006).

Burkholderia pseudomallei was found unequally in soil of the endemic areas. The significant differences of some physicochemical properties of soil in the presence and absence of the bacterium have been reported (Ngamsang et al. 2015; Palasatien et al. 2008). Biological interactions of microbes in soil especially during rainy seasons, either by antagonism or mutualism, could also influence the microbial community. A similar situation was already reported, in that the phages capable of infecting B. pseudomallei were found mostly in the soil without this bacterium (Withatanung et al. 2016). If microbial communities in the presence and absence of $B$. pseudomallei were significantly different, soil in the endemic areas in the absence of this bacterium may be a good source to uncover organisms or compounds with inhibition or killing activity against $B$. pseudomalle $i$.

This current study therefore analyzed and compared microbial communities in the presence and absence of B. pseudomallei to search for antagonistic organisms or their compounds with antimicrobial activity that could potentially be used for controlling this drug resistant $B$. pseudomallei and other pathogens in the future.

\section{Materials and methods}

\section{Bacteria}

Nine isolates of clinical, seven environmental, four ceftazidime resistant and six mutants of B. pseudomalle $i$ were obtained for the study and were kindly provided by Prof. Don Wood, Canada, and Assistant Prof. Dr. Preecha Homchampa, Khon Kaen University and five Burkholderia thailandensis isolates were from the Melioidosis Research Center, Khon Kaen University. Three Burkholderia mallei isolates were kindly provided by Prof. Sumalee Tungpradubkul, Mahidol University, Thailand. Enterococcus sp., Streptococcus pneumonia, Stenotrophomonas maltophilia, Klebsiella pneumonaie, Acinetobacter baumannii, Salmonella group D, Pseudomonas aeruginosa, Shigella group D, Vibrio parahaemolyticus, Escherichia coli and Proteus vulgaris were obtained from Srinagarind hospital, Faculty of Medicine, Khon Kaen University. All of bacterial strains including Bacillus amyloliquefaciens KKU1 (MRCKKU84) were deposited in the culture collection belonging to World Data Centre for Microorganisms (WDCM) (Registration Number 1130).

\section{Soil sampling and culture}

Fifty soil samples were taken a few weeks after rainy season from a $2 \mathrm{~km}^{2}$ area belonging to the Faculty of Agriculture, Khon Kaen University, Khon Kaen province in the northeast of Thailand. The sampled area was composed of grasses and small shrubs and had been left uncultivated for several years. Soil samples were randomly collected at a 15-cm depth and kept tightly sealed in plastic bags in the dark at ambient temperature until they were transported to the laboratory. Microbes in soil samples were cultured on the Ashdown's selective medium and enrichment method the next day to identify the presence or absence of B. pseudomallei (Limmathurotsakul et al. 2012; Wuthiekanun et al. 1990). The positive soil samples for $B$. pseudomallei were counted from both direct and enrichment cultures followed by confirmation of suspected colonies by the latex agglutination test (Samosornsuk et al. 1999). The negative soil samples were determined to be negative by direct and enrichment cultures and also semi-nested PCR detection.

\section{Detection of $B$. pseudomallei in soil}

Total DNA was extracted from each soil sample using the PowerSoil ${ }^{\circledR}$ DNA isolation kit (MO-BIO Laboratories, Carlsbad, CA, USA) according to the manufacture's recommendations and was used to amplify the $16 \mathrm{~S}-23 \mathrm{~S}$ spacer gene by semi-nested PCR that was specific for $B$. pseudomallei (Merritt et al. 2006). The sensitivity of the method to detect B. pseudomallei DNA in soil was evaluated by spiking to obtain $0.1-50 \mathrm{ng}$ of $B$. pseudomalle $i$ DNA in the DNA solution that was extracted from $1 \mathrm{~g}$ soil. Six microliters from each spiking amount were used for the semi-nested PCR.

\section{Physicochemical properties of soil}

The $\mathrm{pH}$, total organic carbon (TOC), total nitrogen (TN), TOC:TN (C:N ratio), exchangeable calcium (EC) and extractable iron (EI) in each soil sample were analyzed as previously described (Ngamsang et al. 2015).

\section{Metagenomics approach for analyzing bacterial community in soil}

Owing to the astonishing diversity of microorganisms present in soils and the fact that approximately only $1 \%$ of them could be cultured in laboratory conditions (Amann et al. 1995), a culture-independent method to identify and compare microbial communities in soil with and without B. pseudomallei was used.

Six positive and three negative soil samples were randomly selected for the study and the data from six positive replicates were analyzed and compared with three negative replicates. Community diversity and similarities were calculated by using both taxonomic and phylogenetic measurements. The taxonomic similarity was calculated as the proportion of shared operational taxonomic units (OTUs), whereas phylogenetic similarity was calculated as the proportion of shared phylogenetic branch lengths between communities. 


\section{Soil DNA extraction}

The total DNA was extracted, quantified, diluted, and stored in a $-20{ }^{\circ} \mathrm{C}$ freezer until used. All soil DNA samples were displayed on a $0.7 \%$ Tris-Acetate-EDTA agarose gel and stained with ethidium bromide to verify their integrity.

\section{Pyrosequencing of $16 \mathrm{~S}$ rRNA gene}

DNA extracted from soil samples was used for the barcoding of the primers for the pyrosequencing (Teixeira et al. 2010). PCR amplification of the hypervariable V4 region of the 16S rRNA gene was performed using the eubacterial primers $563 \mathrm{~F}$ and $802 \mathrm{R}$ as previously described (Teixeira et al. 2010). Equimolar amplicon suspensions obtained from the PCR amplification were subjected to pyrosequencing using a Genome Sequencer FLX system (454 Life Sciences, Branford, CT) at the Michigan State University Genomics Technology Support Facility, East Lansing, MI, USA. The sequence data was deposited under GenBank SRA database: SRP136447.

\section{Sequence analyses and diversity metrics}

Sequence processing and analyses were conducted using the open-source bioinformatics pipeline Quantitative Insights Into Microbial Ecology (QIIME) version 1.8.0 (Caporaso et al. 2010). Following the removal of raw sequences with anonymous bases, the assignment of OTUs was performed on the quality-filtered sequences using the RDP database (Wang et al. 2007). The algorithm search (Edgar 2010), which has an additional power of detecting chimera sequences, was used for OTU-picking based on a de novo approach at a minimum of $97 \%$ sequence identity. Only sequences that passed the quality filter were used for downstream analyses. A randomized selection of 2000 sequences per sample was used for rarefaction. The process was repeated 10 times and results are based on the means of these 10 trials. Sequences were assigned to operational taxonomic units (OTUs) based on 97\% DNA identity using a de novo OTUs-picking protocol. Alpha diversity was calculated using both phylogenetic (PD) and taxonomic (Shannon index) metrics (Faith 1992; Shannon 1948). Beta diversity was calculated using the Bray-Curtis index for taxonomic dissimilarity and weighted by UniFrac for phylogenetic dissimilarity (Lozupone and Knight 2005).

The strict definition of Whittaker's (1975) for alpha diversity as the average richness across all soil samples and for beta diversity as variation in species diversity between samples was used. Sampling was not designed to take into consideration the directional turnover along a gradient of beta diversity (Anderson et al. 2011), owing to patchiness of $B$. pseudomallei presence in soil.

\section{Statistical analyses}

The program SPSS, version 16.0 was used to analyze the physicochemical properties of $B$. pseudomallei-positive and negative soils. The independent samples $t$ test was used when two separate sets of independent data were normally distributed. The non-parametric test, MannWhitney U test, was used when two separate sets of independent data were not normally distributed. A nonparametric test was also used to compare the CFU of Bacillus spp. in positive and negative soil samples.

Alpha diversity values between soil samples were compared using a non-parametric two-sample $t$-test with 999 Monte Carlo permutations. To compare the relative abundances of major phylum-level taxa between samples, a non-parametric $t$-test was carried out based on a bootstrap procedure with 100 permutations. An analysis of the similarities (ANOSIM) test was performed with 99 permutations to check whether soil samples harbored significantly different microbial communities (Clarke 1993). All the statistical analyses were conducted in the QIIME 1.8.0 environment.

\section{Isolation of Bacillus spp. from soil}

Bacillus spp. were cultured from soils that were found to be positive and negative for $B$. pseudomallei using the method as described by Travers (1987) with some modifications. One gram of soil was mixed with $10 \mathrm{ml}$ sterile distilled water and boiled for $5 \mathrm{~min}$. The supernatant was tenfold diluted and $100 \mu \mathrm{l}$ was used to spread on a nutrient agar plate and incubated at $37^{\circ} \mathrm{C}$ for $18-24 \mathrm{~h}$. Bacterial colonies with a morphology of being white and large with wavy, lobed margins like Bacillus spp. were sub-cultured and confirmed by Gram's stain.

\section{Screening for the production of antimicrobial compounds against B. pseudomallei}

A single colony of each Bacillus isolate was grown in Luria-Bertani (LB) broth at $37{ }^{\circ} \mathrm{C}$ for $72 \mathrm{~h}$ and centrifuged at $14,600 \times g$ for 10 min $\left(\right.$ Avanti $^{\circledR} \mathrm{J}$-E, Beckman Coulter, Brea, CA) to obtain the supernatant. The agarwell diffusion method was used to determine antimicrobial activity in the supernatant (Umer et al. 2013). $B$. pseudomallei, as a test organism, was grown in LuriaBertani (LB) broth to reach the log phase and $100 \mu \mathrm{l}$ solution was spread on Mueller-Hinton agar (MHA) plates. The plates were dried and punched using a sterile micropipette tip to obtain 4-6 wells per plate. One hundred microliters of supernatant from each Bacillus spp. were then added into each well and incubated at $37^{\circ} \mathrm{C}$ for $24 \mathrm{~h}$. Clear inhibition zones against B. pseudomallei were observed to indicate antimicrobial activity. Ceftazidime, the drug of choice for $B$. pseudomallei was used as 
a positive control and the production medium was used as a negative control.

\section{Species identification}

Four Bacillus spp. from soil with inhibition activity against B. pseudomallei were identified using DNA sequencing in the $16 \mathrm{~S}$ rDNA region. Genomic DNA from each isolate was extracted using a gDNA extraction RBC kit (RBC ribosicen, Taiwan) and amplified using specific primers and conditions that were specific to Bacillus spp. as previously described (Ghribi et al. 2012). The PCR products were sequenced (First Base laboratories Sdn Bhd, Malaysia) and the nucleotide sequences were used for species identification using the Blast program (https ://blast.ncbi.nlm.nih.gov/Blast.cgi?PAGE_TYPE = Blast Search).

\section{The spectrum of antimicrobial activity}

A single colony of each Bacillus isolate was grown in minimal medium supplemented with $1 \%$ glucose (Jamil et al. 2007) and incubated at $37{ }^{\circ} \mathrm{C}$ for $72 \mathrm{~h}$ to represent secondary metabolites. Bacterial cultures were centrifuged at $14,600 \times g$ for 10 min $\left(\right.$ Avanti $^{\circledR} \mathrm{J}-\mathrm{E}$, Beckman Coulter, Brea, CA) and the supernatant representing secondary metabolites were used to test for their activity or kept at $-20{ }^{\circ} \mathrm{C}$ until being used. One hundred microliters of the metabolites were used to determine the antimicrobial activity against $B$. pseudomallei, Burkholderia spp., B. pseudomallei mutants and other Gram-negative and Gram-positive pathogens by the agar-well diffusion method (Umer et al. 2013).

\section{Partial characterization of the antimicrobial compounds Stability}

For heat stability, $1 \mathrm{ml}$ of the $72 \mathrm{~h}$ metabolites from each isolate was put in $1.5 \mathrm{ml}$ micro-centrifuge tubes and were incubated at either $25,40,60$ or $100{ }^{\circ} \mathrm{C}$ for 15,30 or 45 min using a heating block (Major Science, Saratoga, CA). For $\mathrm{pH}$ stability, the $\mathrm{pH}$ of metabolites were adjusted to have a $\mathrm{pH}$ range from 2 to 14 using $1 \mathrm{~N} \mathrm{HCl}$ or $1 \mathrm{~N} \mathrm{NaOH}$ and left at $4{ }^{\circ} \mathrm{C}$ overnight. Prior to assessing for the antimicrobial activity by the agar-well diffusion method, the $\mathrm{pH}$ was readjusted to $\mathrm{pH}$ 7.0. For proteolytic digestion, Proteinase K (Amresco LLC, OH) was used to digest proteins in the metabolites for 4-30 min according to the manufacturer's instructions and then the enzyme was inactivated and the antimicrobial activity measured using the agar-well diffusion method.

\section{Production of the antimicrobial compounds}

Bacillus amyloliquefaciens KKU1 was cultured in duplicate in $150 \mathrm{ml}$ of Luria Bertani (LB) broth at $37^{\circ} \mathrm{C}$ with $200 \mathrm{rpm}$ shaking. One milliliter of the culture was taken and used to measure OD at $600 \mathrm{~nm}$ at intervals for $96 \mathrm{~h}$. The culture supernatant from each time point was also used to test for the antimicrobial activity against $B$. pseudomallei using the agar-well diffusion method.

\section{The effect of the antimicrobial compounds on cell surface}

Burkholderia pseudomallei and E. coli were grown in LB medium to obtain a cell density of $10^{8}-10^{10} \mathrm{CFU} /$ $\mathrm{ml}$. Fifty microliters of the bacterial cell suspension were incubated with $30 \mu \mathrm{g} / \mu \mathrm{l}$ of precipitated proteins from $B$. amyloliquefaciens KKU1 for $24 \mathrm{~h}$ and $10 \mu \mathrm{l}$ were placed on a $0.20 \mu \mathrm{M}$ pore-size membrane filter (Schleicher \& Schuell, Dassel, Germany) and then processed for EM image observations (Hartmann et al. 2010). EM images were taken using a HITACHI S-3000 N 55 microscope (Hitachi High technology, Japan) at electron energies between 10 and $20 \mathrm{kV}$.

\section{Partial purification of the antimicrobial compounds}

A single colony of $B$. amyloliquefaciens KKU1 was grown in $500 \mathrm{ml} \mathrm{M9} \mathrm{minimal} \mathrm{medium} \mathrm{(Cold} \mathrm{Spring} \mathrm{Harbor}$ protocol) supplemented with $1 \%$ glucose and incubated at $37^{\circ} \mathrm{C}$ for $72 \mathrm{~h}$ before the supernatant was collected by centrifugation at $14,600 \times g$ for $10 \mathrm{~min}\left(\right.$ Avanti $^{\circledR} \mathrm{J}$-E, Beckman Coulter, Brea, CA). The supernatant was precipitated by $40-80 \%$ saturated $\left(\mathrm{NH}_{4}\right)_{2} \mathrm{SO}_{4}$ at $4{ }^{\circ} \mathrm{C}$ and then solubilized with Tris-buffer before being dialyzed against Tris-buffer, $\mathrm{pH} 7.5$ at $4{ }^{\circ} \mathrm{C}$ for $24 \mathrm{~h}$. The percentage that gave highest anti-microbial activity against $B$. pseudomallei was used for a large-scale preparation of the proteins. The concentrations of precipitated proteins were determined by the Bradford technique (Bio-Rad Laboratories, Inc., PA).

\section{Effect of the precipitated proteins on B. pseudomallei}

The precipitated proteins from culture supernatant of $B$. amyloliquefaciens KKU1 isolates were filtered through $0.2 \mu \mathrm{m}$ membranes, adjusted the concentration to $0.025 \mathrm{mg} / \mathrm{ml}$ and then used to determine the minimum inhibitory concentration (MIC) and minimum bactericidal concentration (MBC) by micro-broth dilution (Hoelzer et al. 2011). In brief, the antimicrobial compounds were diluted in 96-well plates by two-fold serial dilutions using MHB. An inoculum dose of $10^{5}-10^{6} \mathrm{CFU} / \mathrm{ml}$ of $B$. pseudomalle $i$ then was added into each well, mixed gently and then incubated at $37{ }^{\circ} \mathrm{C}$ for $24 \mathrm{~h}$. The last concentration that provided a clear solution when compared to the growth control was recorded as the MIC. The MBC was evaluated by pipette from each dilution of the clear wells, diluting with PBS pH 7.2 and then $10 \mu$ of each dilution was dropped onto Ashdown's agar for colony counts. Bacterial cells from the last turbid well were collected and stained with Gram's stain. 
Native-PAGE and SDS-PAGE of crude precipitated proteins from $B$. amyloliquefaciens KKU1

Thirty micrograms of precipitated proteins from culture supernatants of $B$. amyloliquefaciens KKU1 were separated in duplicate using 15\% Native-PAGE (Barboza-Corona et al. 2007). The proteins were separated in duplicate for staining with Coomassie blue and tested for inhibition activity by placing on an LB agar plate spread with $\mathrm{B}$. pseudomallei and incubated at $37^{\circ} \mathrm{C}$ for $24 \mathrm{~h}$. The protein bands with activity were observed as having clear inhibition zones on a $B$. pseudomallei lawn. The active protein bands were cut and eluted by $50 \mathrm{mM}$ Tris-HCL pH 8.0 at room temperature, overnight. The proteins were separated in 15\% SDS-PAGE and stained by the silver staining method (Meng et al. 2012).

\section{Results}

Soil sampling, culture and physicochemical factors of soil Twenty-seven soil samples were found to be positive for B. pseudomallei, 24 by direct culturing on Ashdown's selective medium and three by an enrichment method. The colony counts from direct culture varied from $1 \times 10^{3}$ to $6.6 \times 10^{6}$ colonies/g of soil. For the negative soil site, 23 samples were negative by both direct and enrichment cultures. Two samples, however, were found positive using the semi-nested PCR and were then excluded. The average colony count in positive soil samples was $2.4 \times 10^{5}$ colonies/g of soil.

The $\mathrm{pH}, \mathrm{TN}$ and EI were factors that were significantly different between positive and negative soil samples. The average $\mathrm{pH}$ in both positive and negative soil samples was in the acidic range. The average $\mathrm{pH}$ in the positive soil was $4.3(4.0-4.6)$, while the negative soil was 3.9 $(3.7-4.2)(p<0.05)$. For EI, the positive soil had a higher average EI of $45.4 \mathrm{ppm}$ (16-68 ppm) in comparison to $17.3 \mathrm{ppm}(11-25 \mathrm{ppm})$ observed in negative soil samples $(p<0.05)$. The average of $\mathrm{TN}$ in positive soil was $0.03 \%$ $(0.025-0.032 \%)$ and negative soil was $0.02 \%(0.018-$ $0.028)(p<0.05)$.

\section{Metagenomics approach for analyzing bacterial community in soil}

Over 5000 bacterial sequences per sample were detected and 1000-1400 OTUs were associated with the rarefaction curves calculated with Distance-Based OTUs that showed different patterns between positive and negative soil samples. Soil samples without B. pseudomallei showed higher diversity than positive soil samples (Additional file 1: Figure S1).

There were no measured differences in alpha diversity of observed species between positive and negative soils (Fig. 1). Both estimates at taxonomic (Shannon index) and phylogenetic (Faith's Phylogenetic Diversity) levels using a 97\% identity value for the $16 \mathrm{~S}$ rRNA gene were similar. In contrast, the beta diversity was significantly higher in soils without B. pseudomallei. The community similarities as measured both phylogenetic (UniFrac) $(t=-4.1, p<0.001)$ and taxonomically (Bray-Curtis) $(t=-4.68, p<0.001)$, were significantly different (Fig. 1$)$.

There were 11 phyla of the Domain Bacteria identified in soil samples associated with the presence and absence of B. pseudomallei, of which the major phyla were Proteobacteria, Actinobacteria, Firmicutes, Chloroflexi, Acidobacteria, Planctomycetes Gemmatimonadetes, AD3, Nitrospirae, WPS-2, and Armatimonadetes (Fig. 2a). A non-parametric $t$ test was carried out in order to compare the frequencies of major bacterial taxa between negative and positive soil samples using a bootstrap procedure with 100 permutations. Results showed the ratios of phyla Acidobacteria (22.57\%) and Armatimonadetes (2.69\%) over other phyla in the positive soil samples were significantly higher than those present in negative soil samples $(p<0.01)$ (Fig. 2b). On the other hand, Actinobacteria (19.5\%) and Firmicutes (19.4\%) were the major phyla significantly higher in relative abundances in the negative soils when compared to those values observed for positive soil samples ( $p<0.05$ and $p<0.01$ ) (Fig. 2b).

Next, comparisons between negative and positive soil samples at bacterial class levels from nine phyla showed the presences of class Bacilli $(p<0.01)$ and Actinobacteria $(p<0.05)$ were significantly higher in the negative soils than the positive ones (Additional file 2: Figure S2). Class Bacilli was increased from 3.82\% ( \pm 0.82 ; 95\% CI) in the positive to $18.75 \%( \pm 18.29 ; 95 \% \mathrm{CI})$ in the negative soils and Actinobacteria was increased from $1.82 \%$ $( \pm 0.58 ; 95 \% \mathrm{CI})$ in the positive to $16.7 \%( \pm 20.71 ; 95 \% \mathrm{CI})$ in the negative soils. In contrast, the largest population that increased in response to the presence of the pathogen was TM1 (Phylum Acidobacteria), which increased from $3.33 \%( \pm 3.06 ; 95 \% \mathrm{CI})$ in negative soils to $8.08 \%$ $( \pm 1.81 ; 95 \% \mathrm{CI})$ in positive soils, followed by Acidimicrobiia (Phylum Actinobacteria) that increased from 2.05\% $( \pm 2.15 ; 95 \% \mathrm{CI})$ to $7.59 \%( \pm 1.15: 95 \% \mathrm{CI})$, and Solibacteres (Acidobacteria) increased from 1.13\% $( \pm 1.36$; $95 \%$ $\mathrm{CI})$ to $3.45 \%( \pm 0.49 ; 95 \% \mathrm{CI})$ (Additional file 3: Figure S3).

\section{Bacillus spp. isolation and species identification}

The class Bacilli was the largest proportion that significantly increased in the negative soil and the isolation of them from soil was expected to obtain a source of antimicrobial compounds. Sixty-Six Bacillus spp. were able to be isolated from both positive and negative soils, of which $68 \%(45 / 66)$ were from the negative soils. All isolates were tested for antimicrobial activity against $B$. pseudomallei and six isolates that gave 

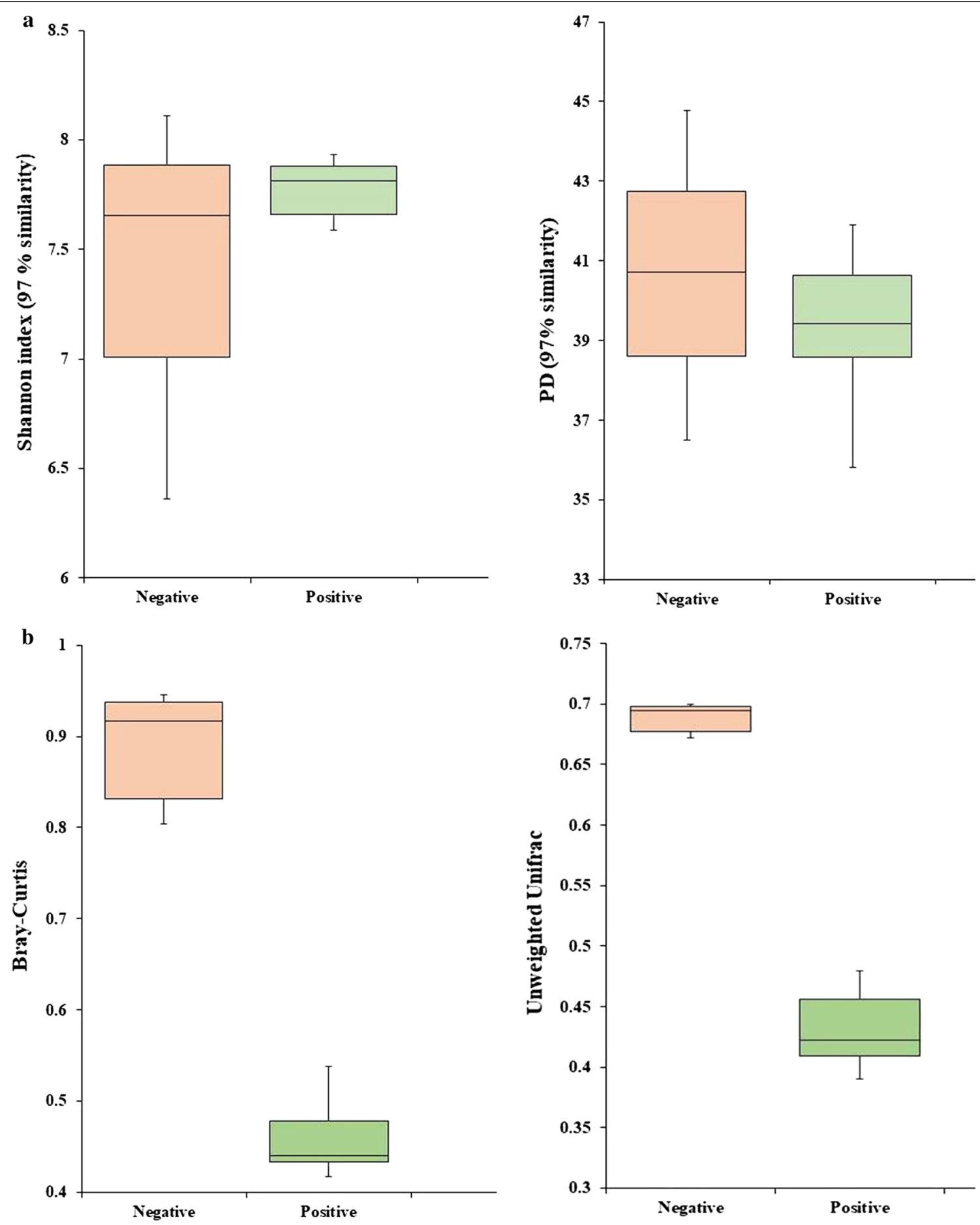

Fig. 1 The comparison of alpha- and beta-diversity between negative and positive soils. a Alpha-diversity (Shannon index and Faith's Phylogenetic Diversity) and $\mathbf{b}$ beta-diversity (Bray-Curtis and unweighted Unifrac distance matrix)

clear zones on B. pseudomallei lawn were obtained only from the negative soil. Two of them (MRCKKU72 and MRCKKU73) were characterized (Boottanun et al. 2017) and other four, named as KKU1 (MRCKKU84),
KKU3 (MRCKKU85), KKU11 (MRCKKU86) and KKU14 (MRCKKU87), are reported here together with diversity of microbes in the presence and absence of B. pseudomallei. PCR amplification at the $16 \mathrm{~S} \mathrm{rDNA}$ 


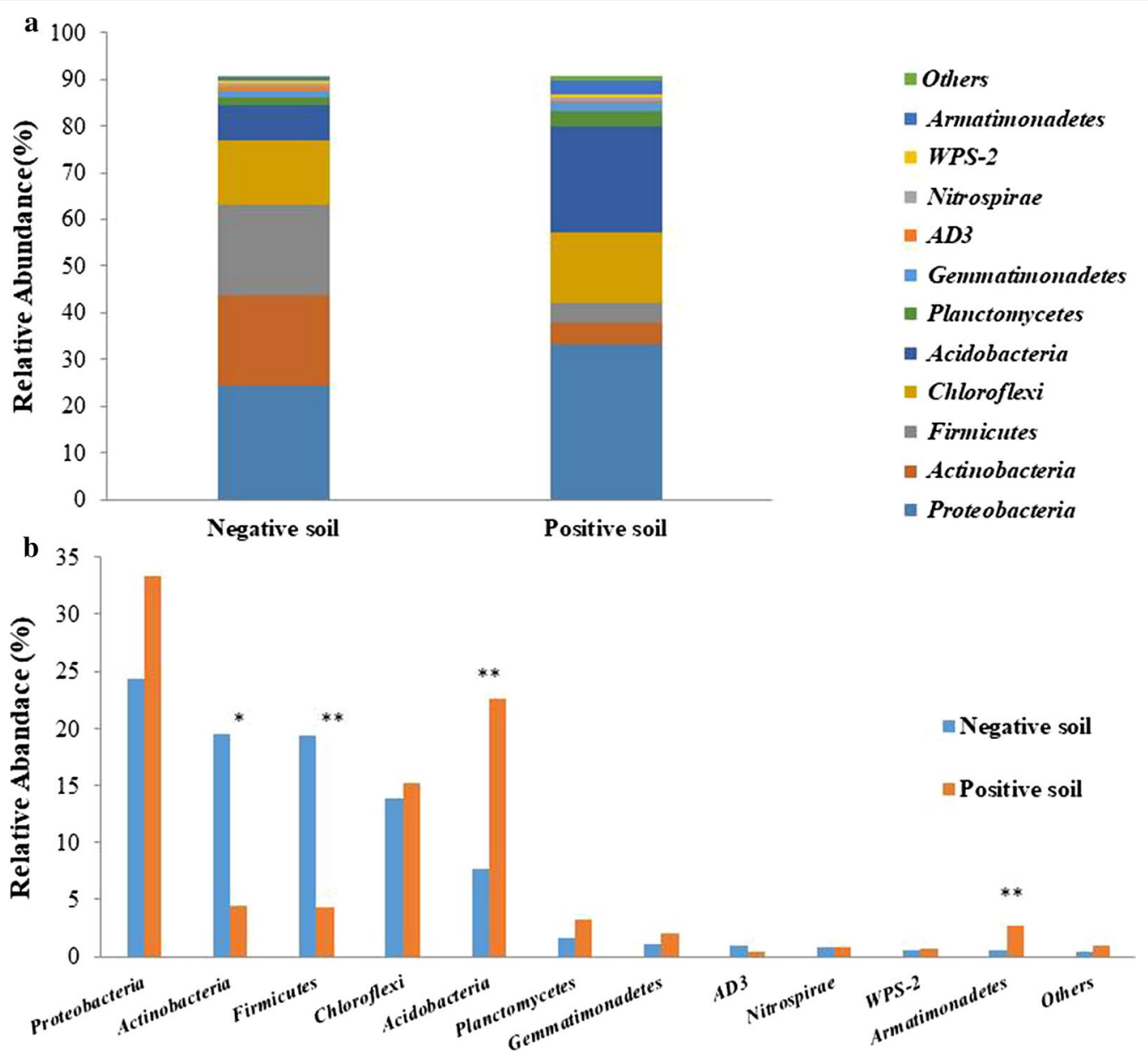

Fig. 2 The comparison of microbial composition in positive and negative soils. a The stack graph of microbes in major phyla. $\mathbf{b}$ The comparisons of each major phyla. The blue bars represent negative soil and orange bars represent positive soil. Asterisks $\left({ }^{*} p<0.05,{ }^{* *} p<0.001\right)$ indicate the taxa that were significantly different in relative abundances of negative and positive soil samples

region of DNA from these isolates to obtain $1500 \mathrm{bp}$ products were analyzed for their nucleotide sequences. The comparison of $16 \mathrm{~S}$ rDNA sequences from four isolates (GenBank Accession number of KKU1, KKU3, KKU11 and KKU14 are BankIt2097833 SequenceKKU1 MH114079, BankIt2097833 SequenceKKU3 MH114080, BankIt2097833 SequenceKKU11 MH114081 and BankIt2097833 SequenceKKU14 MH114082) with the GenBank database revealed nucleotide similarities of 99.8 or $99.9 \%$ with B. amyloliquefaciens (The accession number that matched to the GenBank Accession Number was NC_014551.1).

\section{Spectrum of the antimicrobial activity}

The metabolites from KKU 1, 3, 11 and 14 were tested against B. pseudomallei and Burkholderia spp. (Table 1, Additional file 4: Table S1). KKU 1 and 14 showed broader spectrums of inhibition than others. They could inhibit $50 \%$ of drug resistant isolates, some clinical $(18-45 \%)$ and almost all of the environmental isolates (71-100\%) but not B. thailandensis, a closely related bacterium nor $B$. cepacia. Interestingly, KKU1, 3 and 14 could inhibit $50 \%$ of $B$. mallei which is an important pathogen of the horse that also could infect humans. For mutants and their wild types, the capsule and LPS (O-side chain) mutants were resistant to the metabolites from the four isolates while their wild types were sensitive. Another set of biofilm mutants was vice versa as the wild type showed resistance to the metabolites from all isolates while its mutants were sensitive to KKU1, 3 and 14 (Table 1, Additional file 5: Table S2).

When the metabolites from KKU1 and 14 were selected to test against Gram-positive and Gram-negative pathogens, they could inhibit all Gram-negative bacteria that were tested except $K$. pneumoniae and $A$. baumannii but not Gram-positive (Additional file 6: Table S3). 
Table 1 Antimicrobial activities of culture supernatants from B. amyloliquefaciens against Burkholderia spp

\begin{tabular}{lllll}
\hline Bacterial indicators & KKU1 & KKU3 & KKU11 & KKU14 \\
\hline Bp clinical isolates (9) & 2 & 1 & 3 & 5 \\
Bp environmental isolates (7) & 7 & 5 & 0 & 7 \\
Bp CAZ resistance strains (4) & 2 & 1 & 1 & 2 \\
Bp mutant strains & & & & \\
1026b wild type & $\mathrm{Y}$ & $\mathrm{Y}$ & $\mathrm{Y}$ & $\mathrm{Y}$ \\
SR1015 capsule mutant & $\mathrm{N}$ & $\mathrm{N}$ & $\mathrm{N}$ & $\mathrm{N}$ \\
SRM117 O-side chain mutant & $\mathrm{N}$ & $\mathrm{N}$ & $\mathrm{N}$ & $\mathrm{N}$ \\
$\quad$ MM53 flagellin mutant & $\mathrm{Y}$ & $\mathrm{Y}$ & $\mathrm{N}$ & $\mathrm{Y}$ \\
H777 wild type & $\mathrm{N}$ & $\mathrm{N}$ & $\mathrm{N}$ & $\mathrm{N}$ \\
M10 biofilm mutant & $\mathrm{Y}$ & $\mathrm{Y}$ & $\mathrm{N}$ & $\mathrm{Y}$ \\
M6 biofilm mutant & $\mathrm{Y}$ & $\mathrm{Y}$ & $\mathrm{N}$ & $\mathrm{Y}$ \\
B. thailandensis (5) & 0 & 0 & 0 & 0 \\
B. cepacia (4) & 0 & 0 & 0 & 0 \\
B. mallei (3) & 2 & 2 & 0 & 2 \\
\hline
\end{tabular}

Numbers in brackets indicate number of test isolates

For mutant results, they were placed under their wild type. $Y$ sensitive, $N$ resistant

\section{Effects of proteinase $\mathrm{K}$, temperature and $\mathrm{pH}$} on antimicrobial activity

The antimicrobial activity from KKU1 was abolished when treated with proteinase $\mathrm{K}$ while activities from the other three were partially lost. As antimicrobial peptides were of primary interest, KKU1 was then selected for further study. The antimicrobial activity from KKU1 metabolites was stable when heated at $25-80{ }^{\circ} \mathrm{C}$ for $15-45 \mathrm{~min}$ and $100{ }^{\circ} \mathrm{C}$ for $15 \mathrm{~min}$; then activity was lost when heated to $100{ }^{\circ} \mathrm{C}$ for $30 \mathrm{~min}$. They were stable in a wide range of pHs from 4 to 8 and partially lost at pH 2 and $\mathrm{pH} 12$ (Additional file 7: Table S4).

\section{The production of secondary metabolites with antimicrobial activity}

The metabolites from B. amyloliquefaciens KKU1 showed inhibition activity against $B$. pseudomallei after being cultured for $10 \mathrm{~h}$. The highest inhibition activity was observed at 24-72 $\mathrm{h}$ when the KKU1 entered the stationary growth phase with an inhibition zone of $21 \mathrm{~mm}$ (Fig. 3).

\section{Partial purification of secondary metabolites and their killing activities}

The concentration of precipitated proteins from the culture supernatant of KKU1 was $0.15 \mathrm{mg} / \mathrm{ml}$. The minimum inhibitory concentration (MIC) and minimum bactericidal concentration $(\mathrm{MBC})$ of the precipitated proteins from KKU1 against B. pseudomallei were $0.97 \mu \mathrm{g} / \mathrm{ml}$ and $3.9 \mu \mathrm{g} / \mathrm{ml}$. Ceftazidime, as a positive control, had an MIC and $\mathrm{MBC}$ equal to $2 \mu \mathrm{g} / \mathrm{ml}$ and $4 \mu \mathrm{g} / \mathrm{ml}$. The precipitated proteins from KKU1 inhibited B. pseudomallei at a lower concentration than ceftazidime and could kill the bacterium using similar concentrations.

Precipitated proteins from KKU1, when separated in Native-PAGE and stained with Coomassie Brilliant Blue (Bio-Rad Laboratories Ltd, CA) showed a thick broadened band of approximately $19 \mathrm{kDa}$ and at the dye front (Fig. 4a). Both of them showed clear zones on B. pseudomallei lawn (Fig. 4b). When proteins from clear zone positions were extracted, separated on SDS-PAGE and stained with silver staining, a band of less than $6 \mathrm{kDa}$

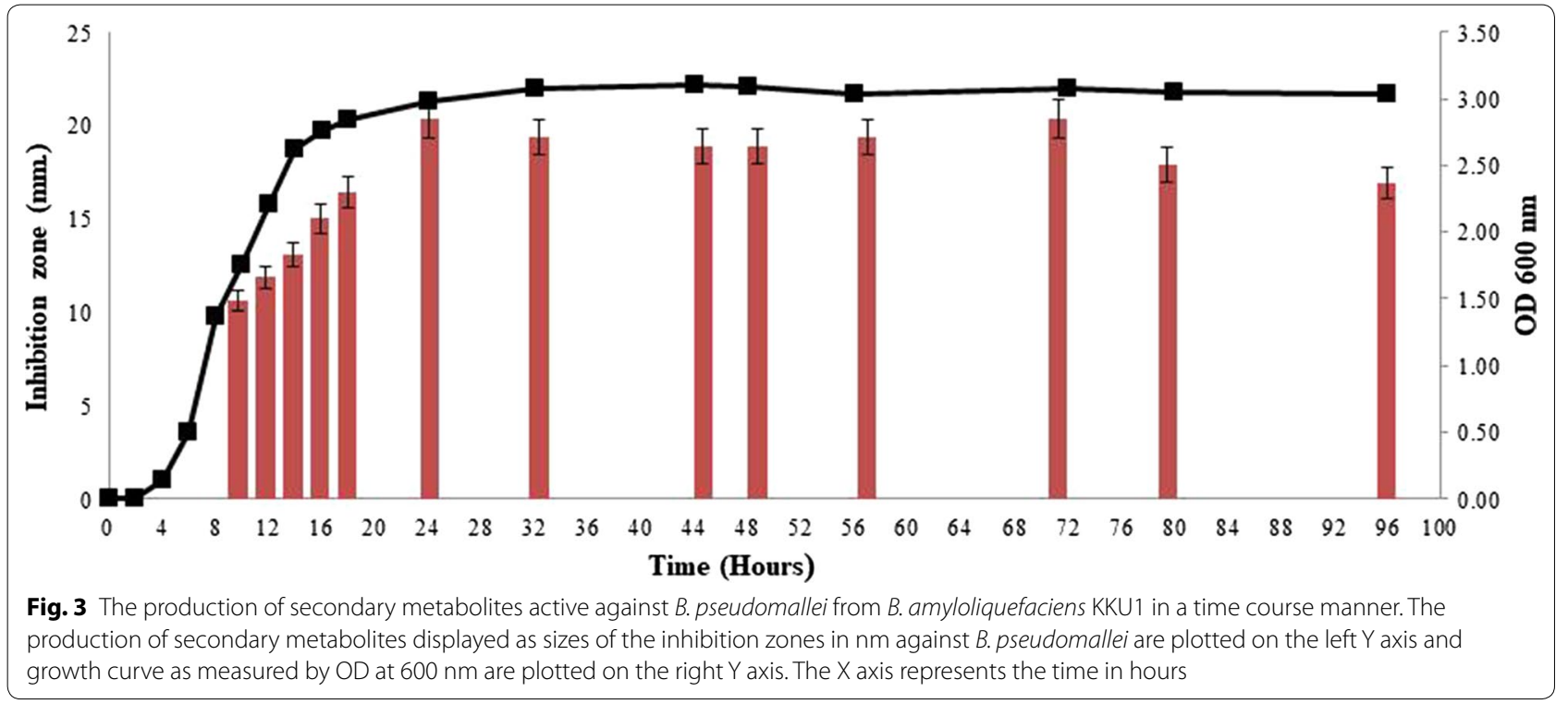




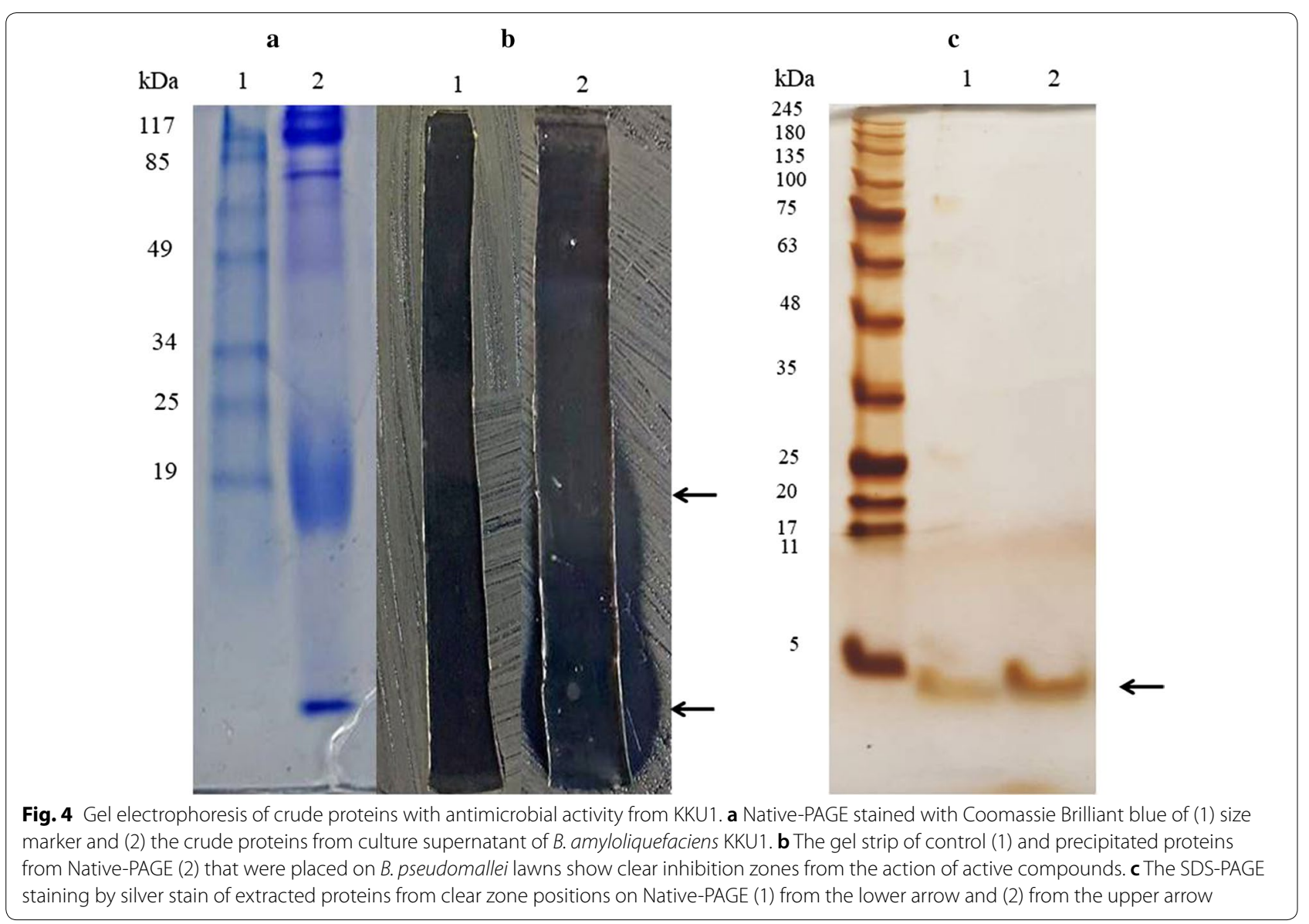

and a thin band at the $19 \mathrm{kDa}$ position can be detected (Fig. 4c).

\section{Bacterial morphology under scanning electron microscope}

The untreated B. pseudomallei and E. coli cells observed under SEM microscopy in standard LB medium appeared as $2-3 \mu \mathrm{m}$ long cells with smooth and intact surfaces (Fig. 5a1, b1). The bacterial cell surfaces that were treated with precipitated proteins for $24 \mathrm{~h}$ showed corrugated surfaces with a somewhat dimpled skin appearance but the average length remained unaltered (Fig. 5a2-3, b2).

\section{Discussion}

A majority of bacterial pathogens that contributed to fatal infections were predicted by the Infectious Disease Society of America to be resistant to at least one of the antibiotics usually used for the treatment of bacterial infections (Hassan et al. 2012). Melioidosis was found to be difficult to treat as the bacterium is intrinsically resistant to several antibiotics and also resistant to its drug of choice, even though rarely (Schweizer 2012). The metagenomics approach was used in this study therefore, not only to explore the diversity and ratio of microbes in each habitat, but the possibility of obtaining a source of compounds that could be active against $B$. pseudomallei.

A few abiotic factors have been reported to be significantly different when compared between soils that were positive and negative for B. pseudomallei (Ngamsang et al. 2015; Palasatien et al. 2008). The factors investigated here were also significantly different in these two groups of soils. It should be noted also that the average $\mathrm{pH}$ values were all in the acidic range that was suitable for $B$. pseudomallei. The C:N ratio of positive soils was found to be lower than the negative soils that favored the decomposition. B. pseudomallei may benefit from this condition as members of the genus Burkholderia are known to be adapted to soil, having large genomes and capable of utilizing multiple C sources (Coenye and Vandamme 2003). It is well known that not only physicochemical properties of soil may influence the diversity and abundance of living organisms, but also biological interactions occurring between different groups of organisms may contribute to the presence of a specific taxon (Anderson et al. 2011; Whittaker 1975). The microbial populations obtained from randomly selected samples for analyses in this study then were affected by both the environmental niche and 


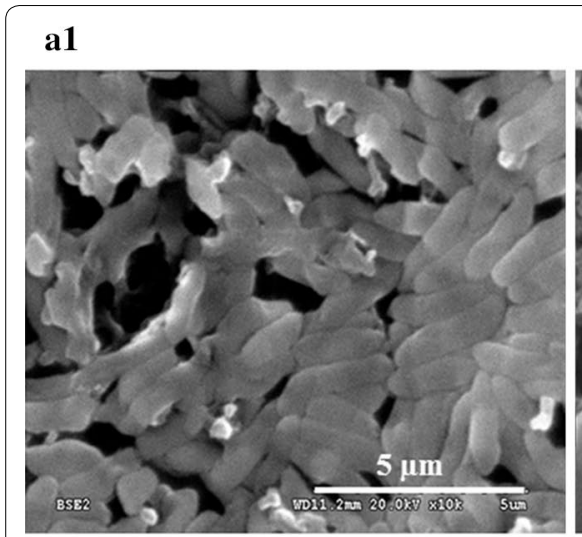

b1

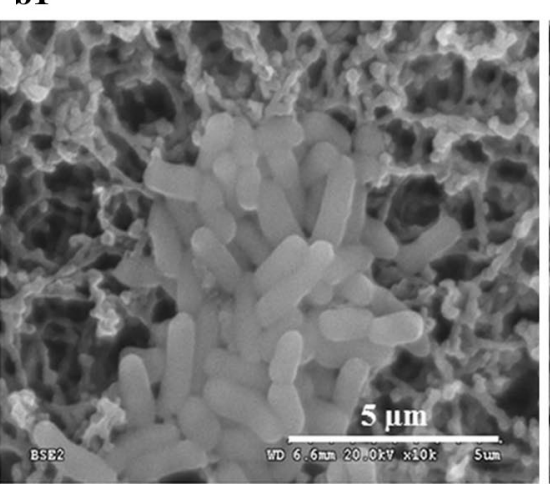

a2

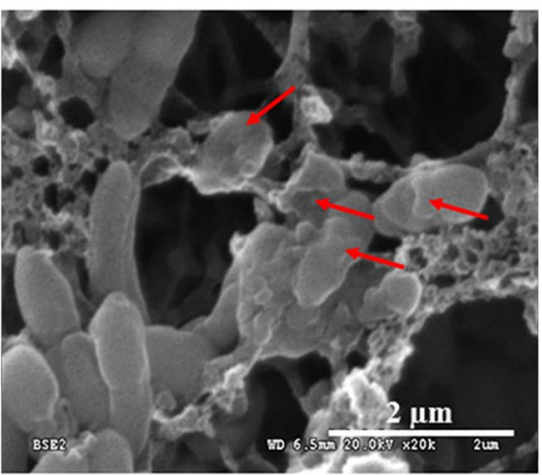

b2 $\mathbf{a 3}$
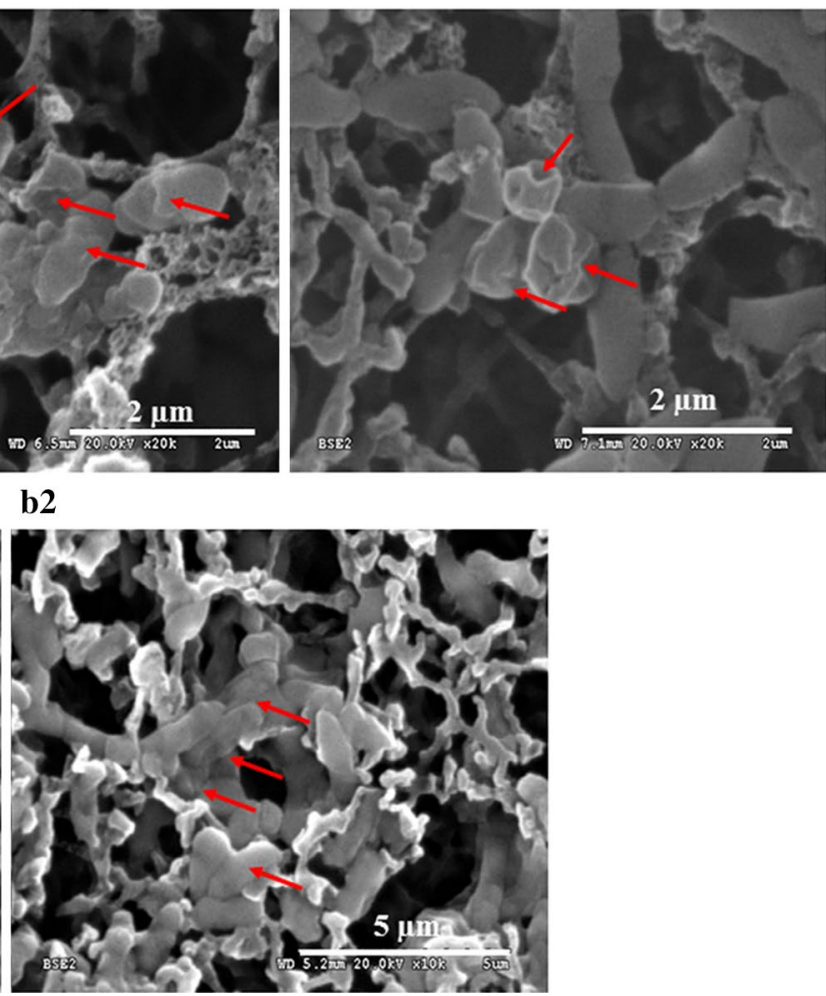

Fig. 5 Scanning electron microscopy shows the effects of B. amyloliquefaciens metabolites on B. pseudomallei and Escherichia coli. a1 B. pseudomallei control, a2-a3 B. pseudomallei treated with precipitated proteins from culture supernatants of B. amyloliquefaciens. Arrows point to damage of bacteria cells. b1 E. coli control and $\mathbf{b} \mathbf{2}$ E. coli treated with precipitated proteins from culture supernatant of B. amyloliquefaciens

microbial interactions that provided existing populations as was cross-sectionally observed in this study.

In this study, while alpha diversity indices (the mean species diversity), both at taxonomic and phylogenetic levels, were similar for positive and negative soils, the beta diversity indices (diversity within habitats) were significantly higher for negative soils. These results suggested that the overall number of microbial taxa in soil is not an important factor in order to limit the presence of $B$. pseudomallei, but the composition of the microbial community may influence this human pathogen success when colonizing the soil environment.

In this study, 11 major phyla were detected in both $B$. pseudomallei positive and negative soil samples. The relative abundances, however, were significantly different for a few groups and the first two phyla, namely Actinobacteria and Firmicutes, were significantly higher in negative in comparison to positive soils. Members in these phyla were known as having potential to secrete antimicrobial agents such as polyketines and antimicrobial peptides that may inhibit B. pseudomallei (Sansinenea and Ortiz 2011). The phylum Actinobacteria is characterized as Gram-positive bacteria that typically found in the soil, playing an important part of decomposition of organic matter (Janssen et al. 2002). Members of this group, such as the genus Streptomyces, contribute to production of several antibiotics that are important in medicine including aminoglycosides, anthracyclines, chloramphenicol, macrolide, and tetracyclines (Qin et al. 2009, 2011). Streptomyces and other Actinomycetes are major contributors to biological buffering of soils and play roles in organic matter decomposition conductive to crop production (Suela Silva et al. 2013). The other phylum is the Firmicutes, Gram-positive bacteria with a low\% $\mathrm{G}+\mathrm{C}$ content (less than 50\%) and constitutes one of the main phyla within the Bacteria with highly diversity in both morphology and lifestyle. In this current study, the relative abundance of members of the class Bacilli were highly increased in negative soils; Bacillus species producing a large number of antimicrobial peptides that could be used as biocontrols for plant diseases (Sansinenea and Ortiz 2011). Specifically, a Bacillus sp. was reported to degrade quorum sensing signal molecules of the $\mathrm{N}$-acylhomoserine lactone (AHLs) in B. pseudomallei culture supernatants and, therefore, could decrease biofilm formation (Ramli et al. 2012). Two biosurfactants 
from Bacillus subtilis and Bacillus licheniformis also have been reported to have specific anti-adhesion activities and selectively inhibit biofilm formation of two pathogenic strains (Wu et al. 2005).

In this study, it was also observed that the relative abundances of phyla Acidobacteria, and Armatimonadetes were significantly higher in positive soils when compared to negative soils. The phylum Acidobacteria is one of the most dominant phyla in soil microbial communities, suggesting that they play an important role in this ecosystem (Lee et al. 2008). This group, however, is very difficult to grow in laboratory conditions and information about their potential metabolic functions in soils is still very limited (Davis et al. 2011). The presence of Acidobacteria group in the positive soils is correlated with the acidic environment found in the presence of $B$. pseudomallei. Whether the bacteria in this phylum highly contribute to the presence of $B$. pseudomallei requires further investigation.

Bacillus species can produce structurally diverse secondary metabolites, which exhibit a wide spectrum of antibiotic activity. These are most commonly known as antimicrobial peptides (AMPs) and are promising alternatives for a new generation of antibiotics against bacteria, fungi and even viruses (Sumi et al. 2015). In the present work, four B. amyloliquefaciens strains produced their secondary metabolites that were active against both clinical and environmental isolates of $B$. pseudomallei and also $B$. mallei, which is an obligate mammalian pathogen and closely related to $B$. pseudomallei. They could also inhibit most of the drug resistant isolates (3/4, 75\%). KKU1, 3 and 14 showed more inhibition against environmental (70-100\%) than clinical isolates (10-50\%). B. amyloliquefaciens acting antagonistically against $B$. pseudomallei in soil that supports the success of isolation of $B$. amyloliquefaciens from soil samples that were negative for B. pseudomallei. Analysis of genomic islands of $B$. pseudomallei could indicate the differences between clinical and environmental isolates (Bartpho et al. 2012). Any contribution from genes found more commonly in the environmental isolates in these regions to the greater susceptibility of environmental isolates to the metabolites of B. amyloliquefaciens, however, needs to be confirmed.

The 16S rDNA sequences from four B. amyloliquefaciens isolates were matched to the same accession number in the GenBank database and the inhibition profiles against other Gram-negative and positive of these four $B$. amyloliquefaciens isolates were similar. Their inhibition profiles against a number of $B$. pseudomallei isolates, however, were different. Therefore, these isolates should remain recognized as different and do not produce the same compounds. They are also different from two isolates that were previously reported from this current group (Boottanun et al. 2017) by observing their inhibition profiles. Restriction enzymes digestion patterns of KKU1, 3 and 11 were similar but different from KKU14 (data not shown).

The metabolites tested against B. pseudomallei mutants and their wild types showed the capsule and LPS (O-side chain) mutants were resistant to the metabolites from the four isolates while their wild types were sensitive. Gram-negative bacteria were reported to have several mechanisms to inhibit natural antimicrobial peptides (AMPs) such as proteolytic degradation, barriers caused by bacterial cell envelopes, such as capsule polysaccharides, biofilm-forming exopolysaccharides, and the $O$-polysaccharides of LPS or the function of the efflux pump (Gruenheid and Le Moual 2012). These barriers were suspected to function as a charge difference as polysaccharides composed of LPS and the capsule had an increased negative charge relative to the outer membrane of the bacteria (Palffy et al. 2009) while AMPs are usually positively charged (Sumi et al. 2015). Capsule and LPS mutants of B. pseudomallei were resistant to $B$. amyloliquefaciens metabolites but not the flagellin mutant while their wild type was not; the charge or structure of these antimicrobial compounds may be different from what has been reported or their action on the target membrane may be different that elimination of LPS or capsule helps facilitate their action. B. thailandensis is a non-pathogenic organism also found in soil and closely related to $B$. pseudomallei but was not affected by these metabolites and, has been reported to contain a different LPS structure from B. pseudomallei (Novem et al. 2009). It is therefore interesting to investigate if this difference plays any role in the resistance to these B. amyloliquefaciens metabolites. In the case of biofilm mutants that are sensitive while their wild type resist, the susceptibilities to $B$. amyloliquefaciens metabolites of B. pseudomalle $i$ were tested in the planktonic but not the biofilm forms. Therefore, the consequences of interrupted genes in the biofilm formation pathway (Taweechaisupapong et al. 2005) rather than the loss of biofilm itself may play a role in the susceptibility of the mutants. Further analysis of these mutants may help understand the mechanism of these metabolites.

Partial characterization of B. amyloliquefaciens metabolites showed the antimicrobial activity from KKU1 was abolished when treated with proteinase $\mathrm{K}$ and was also heat and $\mathrm{pH}$ stable. This was similar to the properties reported in several antimicrobial peptides and bacteriocin-like substances from Bacillus spp. (Hammami et al. 2009; Sutyak et al. 2008). The proteins in native gels from clear zone positions when extracted and separated on SDS-PAGE showed a band of small peptides that were less than $6 \mathrm{kDa}$ and a thin band at the $19 \mathrm{kDa}$ position. 
KKU1 may produce more than one active metabolites similar to B. amyloliquefaciens FZB42 that was reported to produce two ribosomal proteins, plantazolicin (Scholz et al. 2011) and amylocyclicin (Butcher and Helmann 2006). Different species of Bacilli produced a variety of antimicrobial metabolites with different modes of action (Sumi et al. 2015). The SEM observations on $B$. pseudomallei and $E$. coli membranes that were treated with the KKU1 precipitated protein showed membrane destruction. Information from bacteriocins which are cationic peptides that display hydrophobic or amphiphilic properties target the bacterial membrane and cause pore formation (Stein 2005) or complete disintegration of the cell wall (Huang et al. 2009). Translocated peptides were also reported to alter cytoplasmic membrane septum formation, inhibit cell-wall synthesis, nucleicacid synthesis, protein synthesis or enzymatic activity (Brogden 2005). The precipitated proteins from KKU1 could alter membrane septum formation at low concentrations as seen from Gram's stain cell morphology (data not shown) and then membrane destruction at higher concentrations as seen from the SEM images. The MIC and $\mathrm{MBC}$ of the precipitated proteins from KKU1 against B. pseudomallei $(0.97 \mu \mathrm{g} / \mathrm{ml}$ and $3.9 \mu \mathrm{g} / \mathrm{ml})$ were lower than ceftazidime $(2 \mu \mathrm{g} / \mathrm{ml}$ and $4 \mu \mathrm{g} / \mathrm{ml})$ that drawn attention for further characterization.

In conclusion, the metagenomics approach here demonstrated a higher diversity of microbes in soils that were negative for $B$. pseudomallei and for the first time described phyla that were significantly found higher in both positive and negative soils. Intensive investigation in the negative soil could lead to discovery of B. amyloliquefaciens isolates producing a broad spectrum of secondary metabolites that are active against B. pseudomallei and other Gram-negative pathogens but not the Gram-positive bacteria. The metabolites showed a highly potential opportunity to discover new broad-spectrum antibiotics for the treatment of melioidosis and also other Gramnegative infections.

\section{Additional files}

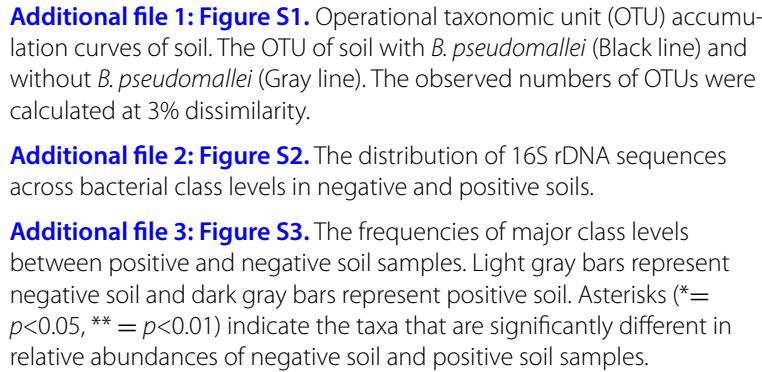

Additional file 1: Figure S1. Operational taxonomic unit (OTU) accumulation curves of soil. The OTU of soil with B. pseudomallei (Black line) and without B. pseudomallei (Gray line). The observed numbers of OTUs were calculated at $3 \%$ dissimilarity.

Additional file 2: Figure S2. The distribution of 165 rDNA sequences across bacterial class levels in negative and positive soils.

Additional file 3: Figure S3. The frequencies of major class levels between positive and negative soil samples. Light gray bars represent negative soil and dark gray bars represent positive soil. Asterisks $\left({ }^{*}=\right.$ $\left.p<0.05,{ }^{* *}=p<0.01\right)$ indicate the taxa that are significantly different in relative abundances of negative soil and positive soil samples.

Additional file 4: Table S1. Antimicrobial activity of supernatants from B. amyloliquefaciens against Burkholderia spp.

Additional file 5: Table S2. Antimicrobial activities of supernatants from B. amyloliquefaciens against B. pseudomallei mutants.

Additional file 6: Table S3. Antimicrobial activities of culture supernatants from B. amyloliquefaciens KKU1 and KKU14 against other pathogenic bacteria.

Additional file 7: Table S4. Effects of $\mathrm{pH}$ on the inhibitory activity of $B$. amyloliquefaciens KKU1 against B. pseudomallei.

\section{Abbreviations}

LB: Luria-Bertani; MHA: Mueller-Hinton agar; MIC: minimum inhibitory concentration; MBC: minimum bactericidal concentration; OTUs: operational taxonomic units; PCR: polymerase chain reaction.

\section{Authors' contributions}

CP: perform most of the experiment and draft manuscript, AWK: analysis of 16SrRNA data and draft analysis results, AB and JR design metagenomics experiments, JR: 16SrRNA sequencing, provide laboratory facilities and draft the manuscript, SW: SEM experiment and draft the manuscript and RW: PI of all grants, design experiments and draft the manuscript. All authors read and approved the final manuscript.

\section{Author details}

${ }^{1}$ Melioidosis Research Center and Department of Biochemistry, Faculty of Medicine, Khon Kaen University, 123 Mitraparb Rd, Muang District, Khon Kaen Province 40002, Thailand. ${ }^{2}$ Department of Biology, University of Texas at Arlington, Arlington, TX, USA. ${ }^{3}$ Department of Microbiology, Faculty of Science, Khon Kaen University, Khon Kaen 40002, Thailand. ${ }^{4}$ Department of Land, Air, and Water Resources, University of California-Davis, Davis, CA, USA. ${ }^{5}$ Melioidosis Research Center and Department of Microbiology, Faculty of Medicine, Khon Kaen University, Khon Kaen, Thailand.

\section{Acknowledgements}

We would like to thank Dr. Klaus Nusslein for sequencing of our soil samples and Dr. Thotsapol Chaianunporn for statistical analysis of soil physicochemical factors and the Melioidosis Research Center, KKU for their facilities support. We would like to thank Prof. James A. Will for editing the manuscript via Publication Clinic, Khon Kaen University, Thailand.

\section{Competing interests}

The authors declare that they have no competing interests.

\section{Available of data and materials}

All data are belonged to the authors and besides what provided in the main manuscript, they were included in the supplement files. All of bacterial strains including Bacillus amyloliquefaciens KKU1 were deposited in the culture collection belonging to World Data Centre for Microorganisms (WDCM) as MRCKKU (Registration Number 1130).

\section{Consent for publication}

Not applicable.

\section{Ethics approval and consent to participate} Not applicable.

\section{Funding}

This project was supported by the Higher Education Research Promotion and National Research University Project of Thailand, Office of the Higher Education Commission, through the heath cluster, project "Specific Health Problems in the Greater Mekong Sub-region (SHeP-GMS)" of Khon Kaen University, Faculty of Medicine invitation research grant, Khon Kaen University (156204) and the Royal Golden Jubilee Ph.D. Program (RGJ:4.O.KK/51/I.1.A. XX).

\section{Publisher's Note}

Springer Nature remains neutral with regard to jurisdictional claims in published maps and institutional affiliations. 
Received: 21 March 2018 Accepted: 17 August 2018

Published online: 24 August 2018

\section{References}

Amann RI, Ludwig W, Schleifer KH (1995) Phylogenetic identification and in situ detection of individual microbial cells without cultivation. Microbiol Rev 59:143-169

Anderson MJ, Crist TO, Chase JM, Vellend M, Inouye BD, Freestone AL, Sanders NJ, Cornell HV, Comita LS, Davies KF, Harrison SP, Kraft NJ, Stegen JC, Swenson NG (2011) Navigating the multiple meanings of beta diversity: a roadmap for the practicing ecologist. Ecol Lett 14:19-28. https://doi.org/ 10.1111/j.1461-0248.2010.01552.x

Barboza-Corona JE, Vazquez-Acosta H, Bideshi DK, Salcedo-Hernandez R (2007) Bacteriocin-like inhibitor substances produced by Mexican strains of Bacillus thuringiensis. Arch Microbiol 187:117-126. https://doi. org/10.1007/s00203-006-0178-5

Barnes JL, Ketheesan N (2005) Route of infection in melioidosis. Emerg Infect Dis 11:638-639. https://doi.org/10.3201/eid1 104.041051

Bartpho T, Wongsurawat T, Wongratanacheewin S, Talaat AM, Karoonuthaisiri N, Sermswan RW (2012) Genomic islands as a marker to differentiate between clinical and environmental Burkholderia pseudomallei. PLOS ONE 7:e37762. https://doi.org/10.1371/journal.pone.0037762

Boottanun P, Potisap C, Hurdle JG, Sermswan RW (2017) Secondary metabolites from Bacillus amyloliquefaciens isolated from soil can kill Burkholderia pseudomallei. AMB Express 7:16. https://doi.org/10.1186/s1356 8-016-0302-0

Brogden KA (2005) Antimicrobial peptides: pore formers or metabolic inhibitors in bacteria? Nat Rev Microbiol 3:238-250. https://doi.org/10.1038/ nrmicro1098

Butcher BG, Helmann JD (2006) Identification of Bacillus subtilis sigma-dependent genes that provide intrinsic resistance to antimicrobial compounds produced by Bacilli. Mol Microbiol 60:765-782. https://doi.org/10.111 1/j.1365-2958.2006.05131.x

Caporaso JG, Kuczynski J, Stombaugh J, Bittinger K, Bushman FD, Costello EK, Fierer N, Pena AG, Goodrich JK, Gordon JI, Huttley GA, Kelley ST, Knights $D$, Koenig JE, Ley RE, Lozupone CA, McDonald D, Muegge BD, Pirrung M, Reeder J, Sevinsky JR, Turnbaugh PJ, Walters WA, Widmann J, Yatsunenko T, Zaneveld J, Knight R (2010) QIIME allows analysis of high-throughput community sequencing data. Nat Methods 7:335-336. https://doi. org/10.1038/nmeth.f.303

Cheng AC, Currie BJ (2005) Melioidosis: epidemiology, pathophysiology, and management. Clin Microbiol Rev 18:383-416. https://doi.org/10.1128/ CMR.18.2.383-416.2005

Clarke KR (1993) Non-parametric multivariate analysis of changes in community structure. Aust J Ecol 18:117-143

Coenye T, Vandamme P (2003) Diversity and significance of Burkholderia species occupying diverse ecological niches. Environ Microbiol 5:719-729

Davis KE, Sangwan P, Janssen PH (2011) Acidobacteria, Rubrobacteridae and Chloroflexi are abundant among very slow-growing and mini-colonyforming soil bacteria. Environ Microbiol 13:798-805. https://doi.org/10.11 $11 / j .1462-2920.2010 .02384 . x$

Edgar RC (2010) Search and clustering orders of magnitude faster than BLAST. Bioinformatics 26:2460-2461. https://doi.org/10.1093/bioinformatics/ btq461

Faith DP (1992) Conservation evaluation and phylogenetic diversity. Biol Conserv 61:1-10

Ghribi D, Abdelkefi-Mesrati L, Mnif I, Kammoun R, Ayadi I, Saadaoui I, Maktouf S, Chaabouni-Ellouze S (2012) Investigation of antimicrobial activity and statistical optimization of Bacillus subtilis SPB1 biosurfactant production in solid-state fermentation. J Biomed Biotechnol 373682:24

Gruenheid S, Le Moual H (2012) Resistance to antimicrobial peptides in Gramnegative bacteria. FEMS Microbiol Lett 330:81-89. https://doi.org/10.111 1/j.1574-6968.2012.02528.x

Hammami I, Rhouma A, Jaouadi B, Rebai A, Nesme X (2009) Optimization and biochemical characterization of a bacteriocin from a newly isolated Bacillus subtilis strain 14B for biocontrol of Agrobacterium spp. strains. Lett Appl Microbiol 48:253-260. https://doi.org/10.1111/j.1472765X.2008.02524.X
Hartmann M, Berditsch M, Hawecker J, Ardakani MF, Gerthsen D, Ulrich AS (2010) Damage of the bacterial cell envelope by antimicrobial peptides gramicidin S and PGLa as revealed by transmission and scanning electron microscopy. Antimicrob Agents Chemother 54:3132-3142. https://doi. org/10.1128/AAC.00124-10

Hassan M, Kjos M, Nes IF, Diep DB, Lotfipour F (2012) Natural antimicrobial peptides from bacteria: characteristics and potential applications to fight against antibiotic resistance. J Appl Microbiol 113:723-736. https://doi. org/10.1111/j.1365-2672.2012.05338.x

Hoelzer K, Cummings KJ, Warnick LD, Schukken YH, Siler JD, Grohn YT, Davis MA, Besser TE, Wiedmann M (2011) Agar disk diffusion and automated microbroth dilution produce similar antimicrobial susceptibility testing results for Salmonella serotypes newport, typhimurium, and 4,5,12:i-, but differ in economic cost. Foodborne Pathog Dis 8:1281-1288. https://doi. org/10.1089/fpd.2011.0933

Huang T, Geng H, Miyyapuram VR, Sit CS, Vederas JC, Nakano MM (2009) Isolation of a variant of subtilosin A with hemolytic activity. J Bacteriol 191:5690-5696. https://doi.org/10.1128/JB.00541-09

Inglis TJ, Sagripanti JL (2006) Environmental factors that affect the survival and persistence of Burkholderia pseudomallei. Appl Environ Microbiol 72:6865-6875. https://doi.org/10.1128/AEM.01036-06

Jamil B, Hasan F, Hameed A, Ahmed S (2007) Isolation of Bacillus subtilis MH-4 from soil and its potential of polypeptidic antibiotic production. Pak J Pharm Sci 20:26-31

Janssen PH, Yates PS, Grinton BE, Taylor PM, Sait M (2002) Improved culturability of soil bacteria and isolation in pure culture of novel members of the divisions Acidobacteria, Actinobacteria, Proteobacteria, and Verrucomicrobia. Appl Environ Microbiol 68:2391-2396

Lee SH, Ka JO, Cho JC (2008) Members of the phylum Acidobacteria are dominant and metabolically active in rhizosphere soil. FEMS Microbiol Lett 285:263-269. https://doi.org/10.1111/j.1574-6968.2008.01232.x

Limmathurotsakul D, Wuthiekanun V, Amornchai P, Wongsuwan G, Day NP, Peacock SJ (2012) Effectiveness of a simplified method for isolation of Burkholderia pseudomallei from soil. Appl Environ Microbiol 78:876-877. https://doi.org/10.1128/AEM.07039-11

Lozupone C, Knight R (2005) UniFrac: a new phylogenetic method for comparing microbial communities. Appl Environ Microbiol 71:8228-8235. https ://doi.org/10.1128/AEM.71.12.8228-8235.2005

Meng QX, Jiang HH, Hanson LE, Hao JJ (2012) Characterizing a novel strain of Bacillus amyloliquefaciens BACO3 for potential biological control application. J Appl Microbiol 113:1165-1175. https://doi.org/10.111 1/j.1365-2672.2012.05420.x

Merritt A, Inglis TJ, Chidlow G, Harnett G (2006) PCR-based identification of Burkholderia pseudomallei. Rev Inst Med Trop Sao Paulo 48:239-244

Ngamsang R, Potisap C, Boonmee A, Lawongsa P, Chaianunporn T, Wongratanacheewin S, Rodrigues JL, Sermswan RW (2015) The contribution of soil physicochemical properties to the presence and genetic diversity of Burkholderia Pseudomallei. Southeast Asian J Trop Med Public Health 46:38-50

Novem V, Shui G, Wang D, Bendt AK, Sim SH, Liu Y, Thong TW, Sivalingam SP, Ooi EE, Wenk MR, Tan G (2009) Structural and biological diversity of lipopolysaccharides from Burkholderia pseudomallei and Burkholderia thailandensis. Clin Vaccine Immunol 16:1420-1428. https://doi.org/10.1128/ CVI.00472-08

Palasatien S, Lertsirivorakul R, Royros P, Wongratanacheewin S, Sermswan RW (2008) Soil physicochemical properties related to the presence of Burkholderia pseudomallei. Trans R Soc Trop Med Hyg 102(Suppl 1):S5-S9. https://doi.org/10.1016/S0035-9203(08)70003-8

Palffy R, Gardlik R, Behuliak M, Kadasi L, Turna J, Celec P (2009) On the physiology and pathophysiology of antimicrobial peptides. Mol Med 15:51-59. https://doi.org/10.2119/molmed.2008.00087

Qin S, Li J, Chen HH, Zhao GZ, Zhu WY, Jiang CL, Xu LH, Li WJ (2009) Isolation, diversity, and antimicrobial activity of rare actinobacteria from medicinal plants of tropical rain forests in Xishuangbanna, China. Appl Environ Microbiol 75:6176-6186. https://doi.org/10.1128/aem.01034-09

Qin S, Xing K, Jiang JH, Xu LH, Li WJ (2011) Biodiversity, bioactive natural products and biotechnological potential of plant-associated endophytic actinobacteria. Appl Microbiol Biotechnol 89:457-473. https://doi. org/10.1007/s00253-010-2923-6

Ramli NS, Eng Guan C, Nathan S, Vadivelu J (2012) The effect of environmental conditions on biofilm formation of Burkholderia pseudomallei clinical 
isolates. PLoS ONE 7:e44104. https://doi.org/10.1371/journal.pone.00441 04

Robe P, Nalin R, Capellano C, Vogel TM, Simonet P (2003) Extraction of DNA from soil. Eur J Soil Biol 39:183-190

Samosornsuk N, Lulitanond A, Saenla N, Anuntagool N, Wongratanacheewin S, Sirisinha S (1999) Short report: evaluation of a monoclonal antibodybased latex agglutination test for rapid diagnosis of septicemic melioidosis. Am J Trop Med Hyg 61:735-737

Sansinenea E, Ortiz A (2011) Secondary metabolites of soil Bacillus spp. Biotechnol Lett 33:1523-1538. https://doi.org/10.1007/s10529-011-0617-5

Scholz R, Molohon KJ, Nachtigall J, Vater J, Markley AL, Sussmuth RD, Mitchell DA, Borriss R (2011) Plantazolicin, a novel microcin B17/streptolysin S-like natural product from Bacillus amyloliquefaciens FZB42. J Bacteriol 193:215-224. https://doi.org/10.1128/JB.00784-10

Schweizer HP (2012) Mechanisms of antibiotic resistance in Burkholderia pseudomallei: implications for treatment of melioidosis. Future Microbiol 7:1389-1399. https://doi.org/10.2217/fmb.12.116

Shannon CE (1948) A mathematical theory of communication. Bell Syst Tech J. 27:379-423, 623-656

Stein T (2005) Bacillus subtilis antibiotics: structures, syntheses and specific functions. Mol Microbiol 56:845-857. https://doi.org/10.111 $1 / j .1365-2958.2005 .04587 . x$

Suela Silva M, Naves Sales A, Teixeira Magalhaes-Guedes K, Ribeiro Dias D, Schwan RF (2013) Brazilian Cerrado soil actinobacteria ecology. Biomed Res Int 2013:503805. https://doi.org/10.1155/2013/503805

Sumi CD, Yang BW, Yeo IC, Hahm YT (2015) Antimicrobial peptides of the genus Bacillus: a new era for antibiotics. Can J Microbiol 61:93-103. https ://doi.org/10.1139/cjm-2014-0613

Sutyak KE, Wirawan RE, Aroutcheva AA, Chikindas ML (2008) Isolation of the Bacillus subtilis antimicrobial peptide subtilosin from the dairy productderived Bacillus amyloliquefaciens. J Appl Microbiol 104:1067-1074. https ://doi.org/10.1111/j.1365-2672.2007.03626.x

Taweechaisupapong S, Kaewpa C, Arunyanart C, Kanla P, Homchampa P, Sirisinha S, Proungvitaya T, Wongratanacheewin S (2005) Virulence of
Burkholderia pseudomallei does not correlate with biofilm formation. Microb Pathog 39:77-85. https://doi.org/10.1016/j.micpath.2005.06.001

Teixeira LC, Peixoto RS, Cury JC, Sul WJ, Pellizari VH, Tiedje J, Rosado AS (2010) Bacterial diversity in rhizosphere soil from Antarctic vascular plants of Admiralty Bay, maritime Antarctica. ISME J 4:989-1001. https://doi. org/10.1038/ismej.2010.35

Travers RS, Martin PA, Reichelderfer CF (1987) Selective process for efficient isolation of soil Bacillus spp. Appl Environ Microbiol 53:1263-1266

Umer S, Tekewe A, Kebede N (2013) Antidiarrhoeal and antimicrobial activity of Calpurnia aurea leaf extract. BMC Complement Altern Med 13:1472-6882

Wang Q, Garrity GM, Tiedje JM, Cole JR (2007) Naive Bayesian classifier for rapid assignment of rRNA sequences into the new bacterial taxonomy. Appl Environ Microbiol 73:5261-5267. https://doi.org/10.1128/AEM.00062-07

Whittaker RH (1975) Communities and ecosystems. Macmillan Publishers, New York

Wiersinga WJ, Currie BJ, Peacock SJ (2012) Melioidosis. N Engl J Med 367:10351044. https://doi.org/10.1056/NEJMra1204699

Withatanung P, Chantratita N, Muangsombut V, Saiprom N, Lertmemongkolchai G, Klumpp J, Clokie MR, Galyov EE, Korbsrisate S (2016) Analyses of the distribution patterns of Burkholderia pseudomallei and associated phages in soil samples in Thailand suggest that phage presence reduces the frequency of bacterial isolation. PLoS Negl Trop Dis 10:e0005005. https://doi.org/10.1371/journal.pntd.0005005

Wu S, Jia S, Sun D, Chen M, Chen X, Zhong J, Huan L (2005) Purification and characterization of two novel antimicrobial peptides subpeptin JM4-A and subpeptin JM4-B produced by Bacillus subtilis JM4. Curr Microbiol 51:292-296. https://doi.org/10.1007/s00284-005-0004-3

Wuthiekanun V, Dance DA, Wattanagoon Y, Supputtamongkol Y, Chaowagul W, White NJ (1990) The use of selective media for the isolation of Pseudomonas pseudomallei in clinical practice. J Med Microbiol 33:121-126. https://doi.org/10.1099/00222615-33-2-121

\section{Submit your manuscript to a SpringerOpen ${ }^{\odot}$ journal and benefit from:}

- Convenient online submission

- Rigorous peer review

- Open access: articles freely available online

- High visibility within the field

- Retaining the copyright to your article

Submit your next manuscript at $\boldsymbol{\nabla}$ springeropen.com 